\title{
A Study on the Interactive Relationship between Housing Price and Land Price in Beijing-From the Perspective of Co-Integration Analysis and Granger Causality Test
}

\author{
Qimin Lin, Wenjie Liu, Yang Li, Mingze Zhou \\ School of Business Administration, South China University of Technology, Guangzhou, China \\ Email: linqimin2013@foxmail.com
}

Received 25 March 2016; accepted 18 April 2016; published 21 April 2016

Copyright @ 2016 by authors and Scientific Research Publishing Inc.

This work is licensed under the Creative Commons Attribution International License (CC BY). http://creativecommons.org/licenses/by/4.0/

\section{(c) (i) Open Access}

\begin{abstract}
Based on VAR model, this paper employs Granger causality test to analyze the interactive relationship between housing price and land price in Beijing. The main conclusions are as follows: 1) there is a positive co-integration relationship between housing price and land price in Beijing. Without considering other factors, housing price rises an average of 0.41 percent when land price rises 1 percent in the long term so that reducing land price is an effective way to lower housing price; 2) the Granger causality between Beijing housing price and land price changes with the length of time, but on the whole, housing price has a relatively larger impact on land price. Hence, the implication for policy makers is that it is more significant for controlling housing price rather than land price.
\end{abstract}

\section{Keywords}

Housing Price, Land Price, Granger Causality Test

\section{Introduction}

The relationship between land price and housing price has been seen as a priority area of research for a long while. Although many scholars actively explore and research this relationship, there is no final conclusion in the 
theoretical or empirical aspects. That is mainly because there are many factors influencing housing price and land price, and the general analysis cannot explore the regularity. Taking into account the obvious geographical characteristics of real estates, it is more meaningful in the case of understanding regional differences, especially in the in-depth study of taking a certain city as a unit, the corresponding conclusions having certain theoretical and practical values. Most of the existing empirical researches mainly use the national average data to simply analyze the relationship between land price and housing price, ignoring the differences among the various regions [1]. Therefore, considering a single area or city is of certain significance for studying land price and housing price. As the housing price of Beijing is the direction indicator of that of China, the study of the interaction between land price and housing price in Beijing is obviously of great significance.

The paper is organized as follows. Literature review on the relationship between housing price and land price is described in Section 2. This is followed by methods and data, namely Section 3. Section 4 then assesses the empirical results by using Granger causality test. Finally, key conclusions are drawn in Section 5.

\section{Literature Review}

As extant researches on the relationship between housing price and land price can be divided into theoretical and empirical ones, the author review the research on the relationship between housing price and land price from these two perspectives.

\subsection{Theoretical Researches on the Relationship between Housing Price and Land Price}

The fact that land price and housing price tend to present a synchronous rising trend causes great controversy about the relationship between the two, and the mainstream views can be divided into three categories [2] [3]. Firstly, land price promotes housing price. The scholars who support this view mainly analyze the relationship between land price and housing price from the perspective of the cost structure. They believe that the government's bidding, auction and listing to sell of business lands are largely responsible for the soaring land price, which further leads to the rapid rise in housing price [4]. Secondly, housing price pulls land price. The scholars who hold the view deal with this relationship mainly from the perspective of market supply and demand and operation. The demand for real estate causes the demand for land, so housing price that witness an upward trend leads directly to rising land price [5] [6]. Thirdly, land price and housing price interact with each other. From the perspective of space economics, some researchers find that this issue has different conclusions in different conditions as the relationship between housing price and land price is a circular relationship [7]. But Kauko (2003) indicates that the rise in housing price is mainly due to the land policy, because the main impact on the price of housing is produced by the government's land planning and other policies if there is no restriction on the land supply [8].

\subsection{Empirical Researches on the Relationship between Housing Price and Land Price}

Based on the concept that facts speak for themselves, China's scholars also establish a model to illustrate the causality of housing price and land price, by which they use relevant data to do some empirical researches. Holding that land price promotes housing price, Zhang and Zhang (2010) use GIS technology combined with statistical analysis method to research the transaction data of Beijing land market from January 2008 to June 2009 and find that the supply of land affects housing price significantly [9]. For the view that housing price pulls land price, the China's Ministry of Land Resources (2009) want to use the specific data to eliminate the debate. They conducts special investigations to 620 real estate projects that have entered the sales phase since 2006, finding that land price only accounts for a small portion of the sale price, approximately $23 \%$ on average [10]. Supporting the view that land price and housing price interact with each other, some scholars develop various models to analyze the relationship between land price and housing price and believe that this mutual influence cannot let they make an accurate judgment until given a certain condition [11]. Zheng and Wu (2006) summarize the reasons why there exist these divergences into four aspects: 1) Variable selection. Some studies use land transaction price index and housing price index while others use residential price index and residential land transaction price index or general residential sales price index and general residential land index; 2) Time series. In the extant literature, the time series of some studies is too short, which may affect the accuracy of the conclusions of the study; 3) Data processing results. Especially in the iteration of the index over the years, part of the 
studies are wrong; 4) there are problems in the process of Granger causality test, and unit root and co-integration test are not performed in some researches [12].

To sum up, the current theoretical researches are generally unconvincing as they basically do qualitative analysis and normative research from a certain perspective; and the current empirical researches hardly draw consistent conclusions due to the complexity and variety of the relationship between the two. The time series of data sample used in the current literature is relatively short and has a lag period, and most papers are even limited to do simple correlation analysis by using the national average land price and housing price, which also reduces the reliability of the conclusions. It is still necessary to further research the relationship between housing price and land price, especially the empirical research of taking a single city as a unit.

Therefore, this paper employs Beijing's monthly data between February 2003 and November 2013 to make an empirical test about the relationship between housing price and land price on the basis of VAR model.

\section{Methods and Data}

\subsection{Methods}

Granger causality test is a common method to study the causal relationship between two variables. For the two time series processes $X_{t}$ and $Y_{t}$, the study aims to explore whether the lagged term of $X_{t}$ is helpful to the projection of $Y_{t}$. In other words, if the use of $X_{t}$ is better than ignoring $X_{t}$ in the process of predicting $Y_{t}, X_{t}$ is called the Granger reason of $Y_{t}$.

Specifically, when testing whether $X_{t}$ is the Granger reason of $Y_{t}$, it is necessary to establish the p-order lag equation of $Y_{t}$, defined as follows:

$$
Y_{t}=r+\sum_{i=1}^{p} \alpha_{i} X_{t-i}+\sum_{i=1}^{p} \beta_{i} Y_{t-i}+u_{t}
$$

where $Y_{t}$ is the Granger result to be tested (namely endogenous variable); $X_{t}$ is the Granger reason to be tested (namely exogenous variable); $\alpha_{i}$ and $\beta_{i}$ are the coefficients of lagged items of $X_{t}$ and $Y_{t} ; \gamma$ is the constant term; $u_{t}$ is the residual.

After the formula (1) is estimated, this paper constructs F-statistics to test the following joint test:

$$
H_{0}=a_{1}=a_{2}=\cdots=a_{k}=0, i=1,2, \cdots p
$$

If the F-statistics is larger than the critical value on a certain confidence level, the null hypothesis shown in the formula (2) is rejected. Hence, $X_{t}$ is the Granger cause of $Y_{t}$.

As can be seen from the above analysis of the Granger causality test method, the premise hypothesis of the Granger causality test is that $X_{t}$ and $Y_{t}$ are stationary sequences (single integrated) and co-integration sequences.

\subsection{Data}

To reflect the impact of land price on the housing price, the study employs Eviews 7.2, an econometric analysis software, to make a stationary test of housing price and land price, then co-integration test and finally Granger causality test.

All Beijing's data presented herein are derived from the industry statistics database of China Economic Information Network (CEInet). The reason why the study chooses Beijing as the research object is mainly based on two considerations: Firstly, Beijing, as China's political, economic and cultural center, is very representative; secondly, the availability of data. Due to late start of the real estate market, the annual time series of samples are limited so that the study uses the monthly data for analysis, but there are not many cities recording monthly data. The sample space is set from February 2003 to November 2013 (the lack of data of every January), and the sample size is 120 . Housing price is indicated by monthly sales price of commercial housing, represented by HP; land price is indicated by monthly fee investment of per unit area of land acquisition, represented by LP. All units are RMB yuan/square meter.

The study selects the natural logarithms of both HP and LP, denoted as LHP and LLP, to reflect the elasticity of housing price and land price, reduce the degree of dispersion of the sequences, and avoid affecting the dimension. The following empirical tests are all based on LHP and LLP. Descriptive statistics is shown in Table 1. 
Table 1. Descriptive statistics.

\begin{tabular}{ccccc}
\hline & LP & HP & LLP & LHP \\
\hline Mean & $14,070.7932$ & $11,995.4852$ & 9.1192 & 9.2727 \\
Median & 9385.1806 & $11,800.5926$ & 9.1469 & 9.3759 \\
St. dev. & $13,294.86780$ & 5413.40577 & 0.98230 & 0.51344 \\
Min. & 1058.24 & 4515.77 & 6.96 & 8.42 \\
Max. & $62,115.38$ & $19,962.62$ & 11.04 & 9.90 \\
N & 137 & 137 & 137 & 137 \\
\hline
\end{tabular}

\section{Empirical Results}

\subsection{Stationary Test Results of Housing Price and Land Price}

Prior to empirical test, it is necessary to do stationary test of time series variables. This paper uses ADF method to do unit root test of LHP and LLP.

It can be seen from Table 2 that LHP and LLP are smooth sequences, since the ADF statistics of LLP and LLP sequences reject the null hypothesis of unit root at the $1 \%$ significance level. It is clear that the horizontal sequences of residential price and land price are stationary series, which can be analyzed by VAR model. Then the paper selects the lag order of the VAR model and gets corresponding calculation results, as shown in Table 3. According to LR, FPE, AIC, SC and HQ criteria, there are five values of five indicators supporting that VAR (1) model should be established. Therefore, this study chooses to create a VAR (1) model.

\subsection{Co-Integrating Test Results of Housing Price and Land Price}

Horizontal sequences of housing price and land price are stationary series, and if there is the same long-term trend of movement between them, the relationship of the two variables can be considered as the long-term equilibrium co-integration relationship. This paper uses the Johansen maximum likelihood estimation method to test LHP and LLP, the results shown in Table 4. According to Trace test and the maximum Max-Eigen test, the two variables have the co-integration relationship at the $1 \%$ level, which explains that there exists the long-term co-integration relationship between housing price and land price.

Then co-integration equation between LHP and DIP is defined as follows: LHP $=0.41 *$ LLP +5.57 .

LLP is a significant factor and t statistics is 13.39 , which indicate that housing price and land price have a positive co-integration relationship. Without considering other factors, housing price rises an average of $0.41 \%$ when land price rises $1 \%$ in the long term so that reducing land price is an effective way to lower housing price.

\subsection{Causality Test Results for Housing Price and Land Price}

Variables LHP and LLP are stationary series and have the co-integration relationship, but the VAR model built by the LHP and LLP is also smooth. Hence, Granger causality test can be carried out on the LHP and LLP directly. During the inspection process, different lag orders are taken to reflect the short-term and long-term Granger causality of LHP and LLP, and test results are shown in Table 5.

As can be seen from Table 5, when the lag phase is 1, the Beijing's land price are the Granger cause of housing price, while housing price is also the Granger cause of land price; when the lag phase is 2, land price is not the Granger cause of housing price, but housing price is the Granger cause of land price; when the lag phase varies from 3 to 9, it can be found from F-statistics that the impact on the land price is greater than the impact on housing price, though there is no significant relationship between housing price and land price.

Overall, in a very short term, land price and housing price show a certain relationship, and land price and housing price are the Granger causes of each other; in the medium term, though there is no significant relationship between land price and housing price, the impact on the land price is greater than the impact on housing price. Hence, housing price has a relatively larger impact on land price on the whole.

Ai et al. (2008) indicate that there is a two-way Granger causality between housing price and land price in Beijing when lag phase is 1 or 3; land price is the Granger cause of housing price but not vice versa when lag 
Table 2. Unit root test results of LHP and LLP.

\begin{tabular}{ccccc}
\hline Variable & Test form $(\mathrm{C}, \mathrm{T}, \mathrm{K})$ & ADF statistics & $1 \%$ critical value & Probability \\
\hline LLP & $(0,0,0)$ & -12.945 & -0.589 & 0.000 \\
LHP & $(0,0,0)$ & -11.682 & -2.589 & 0.000 \\
\hline
\end{tabular}

Table 3. Lag order selection of the VAR model.

\begin{tabular}{|c|c|c|c|c|c|c|}
\hline Lag & LogL & LR & FPE & AIC & $\mathrm{SC}$ & HQ \\
\hline 0 & -97.50699 & NA & 0.073241 & 3.061753 & 3.128658 & 3.088151 \\
\hline 1 & 158.5638 & $488.5043^{* *}$ & $3.14 \mathrm{e}^{-}-05^{* *}$ & $-4.694271^{* *}$ & $-4.493559^{* *}$ & $-4.615077^{* *}$ \\
\hline 2 & 161.0149 & 4.525052 & $3.29 e^{-}-05$ & -4.646612 & -4.312091 & -4.514622 \\
\hline 3 & 161.4766 & 0.824055 & $3.67 e^{-05}$ & -4.537743 & -4.069413 & -4.352957 \\
\hline 4 & 162.9664 & 2.566961 & $3.98 e^{-}-05$ & -4.460505 & -3.858367 & -4.222923 \\
\hline 5 & 165.0096 & 3.394844 & $4.24 \mathrm{e}^{-}-05$ & -4.400295 & -3.664349 & -4.109917 \\
\hline
\end{tabular}

** Denote significance at the $95 \%$ level of confidence.

Table 4. Co-integrating test results of LHP and LLP.

\begin{tabular}{cccccc}
\hline \multirow{2}{*}{$\begin{array}{c}\text { Maximum } \\
\text { co-integration rank }\end{array}$} & Eigenvalues & Trace Statistics & 1\% critical value & $\begin{array}{c}\text { Max-Eigen } \\
\text { Statistics }\end{array}$ & $1 \%$ critical value \\
\cline { 3 - 6 } & 0.173408 & 21.34102 & 19.93711 & 20.75838 & 18.52001 \\
$0^{* * * *}$ & 0.005331 & 0.582639 & 6.634897 & 0.582639 & 6.634897 \\
\hline
\end{tabular}

${ }^{* * *}$ Denote significance at the $99 \%$ level of confidence.

Table 5. Granger causality test results of LHP and LLP.

\begin{tabular}{lllll}
\hline \multicolumn{1}{c}{ Hypothesis } & Lag phase & F-statistics & P-value & Conclusion \\
\hline LLP is not a Granger cause of LHP. & 1 & $9.96837^{* * *}$ & 0.0021 & Reject \\
LHP is not a Granger cause of LLP. & 1 & $4.32242^{* *}$ & 0.0400 & Reject \\
LLP is not a Granger cause of LHP. & 2 & 1.41757 & 0.2475 & Accept \\
LHP is not a Granger cause of LLP. & 2 & $2.65400^{*}$ & 0.0757 & Reject \\
LLP is not a Granger cause of LHP. & 3 & 0.34266 & 0.7945 & Accept \\
LHP is not a Granger cause of LLP. & 3 & 1.92835 & 0.1316 & Accept \\
LLP is not a Granger cause of LHP. & 4 & 0.06886 & 0.9911 & Accept \\
LHP is not a Granger cause of LLP. & 4 & 1.48405 & 0.2169 & Accept \\
LLP is not a Granger cause of LHP. & 5 & 0.37367 & 0.8645 & Accept \\
LHP is not a Granger cause of LLP. & 5 & 1.27577 & 0.2878 & Accept \\
LLP is not a Granger cause of LHP. & 6 & 0.34278 & 0.9100 & Accept \\
LHP is not a Granger cause of LLP. & 6 & 0.46657 & 0.8290 & Accept \\
LLP is not a Granger cause of LHP. & 7 & 0.37834 & 0.9072 & Accept \\
LHP is not a Granger cause of LLP. & 7 & 0.40981 & 0.8880 & Accept \\
LLP is not a Granger cause of LHP. & 8 & 0.36862 & 0.9214 & Accept \\
LHP is not a Granger cause of LLP. & 8 & 0.29208 & 0.9579 & Accept \\
LLP is not a Granger cause of LHP. & 9 & 0.37622 & 0.8762 & Accept \\
LHP is not a Granger cause of LLP. & 9 & 0.85847 & 0.6451 & A
\end{tabular}

${ }^{*}$ Denote significance at the $90 \%$ level of confidence. ${ }^{* *}$ Denote significance at the $95 \%$ level of confidence. ${ }^{* * *}$ Denote significance at the $99 \%$ level of confidence. 
phase is 2 or 4; there is no significant Granger causality between housing price and land price when lag phase is above 5 [13]. This shows that the empirical results of this paper are not consistent with the research results of Ai et al. (2008), of which one possible reason is the difference of selected periods. But the findings of this paper are highly similar with that of Hao and Wang (2012): there is a long-term stable equilibrium relationship between housing price and land price, and the elasticity of housing price is greater than the elasticity of land price [14]. Taking housing price and land price data from February 2002 to November 2011 as analytical samples, they use unit root test, Granger causality test, error correction model and measurement methods of variance decomposition to analyze the dynamic relationship between land price and housing price. As can be seen from the co-integration equation, the long-term elasticity of the impact on housing price is 0.44 , which indicates that if land price increases by $1 \%$, housing price will increase by $0.44 \%$ in China; the long-term elasticity of the impact on land price is 1.88 , which indicates that if housing price increases by $1 \%$, land price will increase by $1.88 \%$. Thus, in the long run, housing price has greater contribution to land price.

\section{Conclusions}

Based on the VAR model, this paper employs the data of Beijing's housing price and land price in 2000-2013 and Granger causality test to empirically analyze the interaction relationship between Beijing's housing price and land price. The main two conclusions are as follows:

Firstly, there is a positive co-integration relationship between housing price and land price in Beijing. Without considering other factors, housing price rises an average of 0.41 percent when land price rises 1 percent in the long term so that reducing land price is an effective way to lower housing price. Secondly, the Granger causality between housing price and land price of Beijing can be divided into two phases: in a short term, land price and housing price show a certain relationship, and land price and housing price are the Granger causes of each other; in the medium term, though there is no significant relationship between land price and housing price, the impact on the land price is greater than the impact on housing price. This supports the view that "housing price pulls land price" indirectly.

Based on the complex relationship between housing price and land price and the two main conclusions, it is clear that the relationship between housing price and land price is not the same in different time periods of performance. In the short term, as housing price and land price are the mutual Granger causes, the government should start from both the housing market and land market, using two-pronged approaches to prevent sharp fluctuations in housing price or land price; in the medium term, the relationship between the two is not significant, but the government should focus on the situation of the residential market, as housing price's impact is greater than land price's impact on the whole; in the long term, in order to better control the rise and fall of housing price, the government must control the land price and strengthen the land management. Hence, considering the feasibility of the policy, the government should focus on the related work of land management, and steadily promote urbanization.

\section{References}

[1] Kong, Y. (2010) The Relationship between Land Price and Real Estate Price. Journal of Chongqing University: Social Science Edition, 16, 21-26.

[2] Wang, Y.-L. and Wu, P. (2009) Re-Inspection on the Relationship between Housing Price and Land Price-From the Panel Data of China's 28 Provinces. NANKAI Economic Studies, No. 4, 131-143.

[3] Kuang, W.-D. and Li, T. (2012) Land Sale Pattern, Land Price and Real Estate Price. Journal of Financial Research, No. 8, 56-69.

[4] Bao, Z.-H. (2004) How to Look at China’s Housing Price. Urban Development, No. 1, 18-19.

[5] Zhu, D.-L. and Dong, M.-L. (2005) Economic Analysis of Land Price and Housing Price. China Land, No. 7, $20-21$.

[6] Xu, L. (2009) The Determinants of Urban Housing Price and Land Price in China and Their Relationships. Public Finance Research, No. 11, 10-13.

[7] Yan, J.-H. (2006) Land Price and Housing Price in China: A Theoretical and Empirical Study. Journal of Quantitative \& Technical Economics, 23, 17-26.

[8] Kauko, T. (2003) The Importance of the Context and the Level of Analysis. Druid Working Papers, 20, 134-136. http://dx.doi.org/10.1080/14036090310020885

[9] Zhang, Z.-L. and Zhang, Y.-S. (2010) Present Situation of Land Supply Planning and Land Market Transaction in Bei- 
jing. Social Sciences of Beijing, No. 1, 27-32.

[10] Lou, W.-L. and Hu, X.-M. (2012) Review on the Studies of the Relationship between Housing Price and Land Price. Inquiry into Economic Issue, No. 1, 38-42.

[11] Wen, H.-Z., Lv, X.-M. and Zhang, L. (2010) The Endogeneity and Interaction of Housing Price and Land Price: An Empirical Analysis Based on the Simultaneous Equations Model. Finance \& Trade Economics, No. 2, 124-129.

[12] Zheng, Q.-E. and Wu, C.-F. (2006) Causality between Land Price and Housing Price: A Quantitative Study on Country Level and City Level. China Land Science, 20, 31-37.

[13] Ai, J.-G., Ding, L.-Y. and He, S.-B. (2008) Analysis of the Interrelationship between Housing Price and Land Price: A Study Based on the Data of Beijing, Shanghai and Wuhan. Urban Studies, No. 1, 77-83.

[14] Hao, S.-Y. and Wang, W.-P. (2012) The Dynamic Relationship Research between House Price and Land Price in China. On Economic Problems, No. 9, 36-45. 